\title{
AWAKE CRANIOTOMY USING DEXMEDETOMIDINE INFUSION AND SCALP BLOCK: OUR EXPERIENCE IN SERIES OF CASES
}

B. Annapurna Sarma ${ }^{1}$, P. Sateesh Kumar², B. Muralikrishna ${ }^{3}$

\section{HOW TO CITE THIS ARTICLE:}

B. Annapurna Sarma, P. Sateesh Kumar, B. Muralikrishna. "Awake Craniotomy Using Dexmedetomidine Infusion and Scalp Block: Our Experience in Series of Cases". Journal of Evolution of Medical and Dental Sciences 2015; Vol. 4, Issue 51, June 25; Page: 8924-8929, DOI: 10.14260/jemds/2015/1292

ABSTRACT: BACKGROUND: Awake craniotomy is an important technique used for brain tumour excision from eloquent cortex. Awake craniotomy allows maximum resection of the tumor with minimum functional impairment. The critical aspect is to maintain adequate analgesia and sedation, hemodynamic stability, airway safety, while keeping the patient awake and cooperative for neurological testing. AIM OF THE STUDY: We are reporting cases series of awake craniotomy under monitored anesthesia care using dexmedetomidine infusion as an adjuvant to scalp block, titrating the sedation level by BIS monitoring. MATERIALS AND METHODS: After careful patient selection and psychological preparation Monitored Anesthesia Care was provided by continuous infusion of dexmedetomidine at a rate of $0.2-0.5 \mathrm{ug} / \mathrm{kg} / \mathrm{min}$ titrating sedation score to BIS value of $70-90$. Bilateral scalp block was administered using $0.5 \%$ bupivacaine. For dura mater incision, a pad with $2 \%$ lidocaine was applied for 3 minutes. The tumor removal was complete with no neurological deficiency. All the patients were discharged on $5^{\text {th }}$ postoperative day without complications and with full patient satisfaction. CONCLUSION: We conclude that monitored anesthesia care with dexmedetomidine infusion and scalp block for awake craniotomy is safe and efficacious. Absence of complications and high patient satisfaction score makes this technique close to an ideal technique for awake craniotomy.

KEYWORDS: Awake craniotomy; Dexmedetomidine; Scalp block; BIS index.

INTRODUCTION: Awake craniotomy for epilepsy surgery has been routine for many years. It is now also used for the resection of tumours located in the eloquent cortex.1,2 The challenges for anesthesiologists are performing sedation-analgesia and assuring cardiorespiratory stability without interfering with electrophysiologic monitoring and cognitive tests. Selection of drugs with rapid onset of action, easy titration, with minimal effects on cardiovascular and respiratory systems, which do not interfere with the neurological assessment, is crucial. Moreover, careful selection of patients, high levels of motivation, and psychological and emotional preparation are key elements for a successful procedure. ${ }^{3}$

Bispectral analysis is increasing in popularity for the monitoring of conscious level during anesthesia and sedation. The bispectral index correlates with hypnotic component of anesthesia and was used as a guide to the administration of dexmedetomidine infusion in our cases. ${ }^{4}$

The aim of this cases report was to present a sedation technique with dexmedetomidine infusion combined with scalp block for intracranial tumor resection under awake craniotomy. This technique allowed the main surgical steps without the occurrence of major complications, such as psychomotor agitation, hemodynamic changes, over sedation or airway manipulation and mainly, it did not affect the patients' cognitive evaluation. 
MATERIAL AND METHODS: After obtaining Institutional ethics board approval and written consent five patients of intracranial tumors were enrolled were awake craniotomy. The patients' details were shown in the table. The routine blood investigations were normal; the patients did not have any other systemic illnesses.

\begin{tabular}{|c|c|c|c|c|c|c|}
\hline $\begin{array}{c}\text { Case } \\
\text { Sl. } \\
\text { No. }\end{array}$ & $\begin{array}{l}\text { Age } \\
\text { (yrs) }\end{array}$ & Sex & $\begin{array}{c}\text { Weight } \\
\text { (kg) }\end{array}$ & $\begin{array}{l}\text { Presenting } \\
\text { symptom }\end{array}$ & Diagnosis & $\begin{array}{c}\text { Duration of } \\
\text { surgery } \\
\text { (hours) }\end{array}$ \\
\hline 1 & 45 & Male & 72 & $\begin{array}{c}\text { Seizures, right } \\
\text { upper limb } \\
\text { weakness }\end{array}$ & $\begin{array}{l}\text { Right frontal } \\
\text { glioma }\end{array}$ & 3 \\
\hline 2 & 31 & Male & 65 & Partial seizures & $\begin{array}{l}\text { Left premotor } \\
\text { and motor strip } \\
\text { glioma }\end{array}$ & 3.5 \\
\hline 3 & 22 & Female & 55 & $\begin{array}{l}\text { Headache, } \\
\text { seizures }\end{array}$ & $\begin{array}{c}\text { Left patietal } \\
\text { opecular glioma }\end{array}$ & 4 \\
\hline 4 & 33 & Female & 67 & Seizures & $\begin{array}{c}\text { Left parietal } \\
\text { glioblastoma } \\
\text { multiform }\end{array}$ & 3.0 \\
\hline 5 & 26 & Female & 60 & seizures & $\begin{array}{l}\text { Right frontal } \\
\text { glioma }\end{array}$ & $\begin{array}{l}\text { Converted to } \\
\text { general } \\
\text { anesthesia due } \\
\text { to uncontrolled } \\
\text { seizures }\end{array}$ \\
\hline
\end{tabular}

All members of the team were briefed in advance so that a calm atmosphere prevails in the operating room. On arrival into operation theatre two 18G IV cannulae were inserted and pantocid $40 \mathrm{mg}$ for acid prophylaxis, midazolam $1 \mathrm{mg}$ for anxiolysis, ondonsetron $4 \mathrm{mg}$ antiemetic, fentanyl $100 \mathrm{ug}$ for analgesia and levetiracetam $500 \mathrm{mg}$ for seizure prophylaxis were administered intravenously. Oxygen $3 \mathrm{~L} / \mathrm{min}$ was administered through nasal prongs.

The patient was continuously monitored for ECG, oxygen saturation, noninvasive blood pressure, end tidal $\mathrm{CO} 2$ and level of sedation by bispectal index. The bladder was catheterised because of prolonged duration of procedure and as there is need for mannitol infusion.

Before placing the patient into operative position bolus dose of dexomedetomidine infusion $1 \mathrm{ug} / \mathrm{kg}$ administered over 20minutes, followed by continuous infusion at a rate of 0.2 $0.5 \mathrm{mcg} /$ minute (Titrated BIS index to 70-90). The patient was placed in supine position with head slightly rotated operative side facing up. Care was taken for adequate visibility of the patient to anaesthesiologist during intraoperative testing. Fentanyl 20mcg IV was administered intermittently to provide additional analgesia and patient comfort.

Supraorbital, supratrochlear, zygomaticofacial, auriculotemporal, greater auricular, greater and lesser occipital nerves were blocked using $20 \mathrm{ml}$ of $0.5 \%$ bupivacaine, limiting total dose to $3 \mathrm{mg} / \mathrm{kg}$ body weight. 
In Addition 1\% lignocaine was infiltrated at the three head holder pin sites and along skin incision line. Adrenaline $(5 \mathrm{ug} / \mathrm{mL})$ was added to minimizes acute rises in plasma anaesthetic concentration and maximise the duration of the block..$^{5} 20 \mathrm{gms}$ mannitol was infused about $15 \mathrm{~min}$ prior to completion of craniotomy. Cotton lint's soaked in 1\% lignocaine was applied over dura to provide analgesia during dural opening. On dural opening, brain was found to be relaxed and pulsating. For localization of primary motor cortex, patients were asked to "move toes/fingers, squeeze the ball" and they are well educated and trained about these tasks in preoperative visits. The procedures have lasted for about 3-4 hours. At the end of the surgery, all the patients except one were fully awake and communicating. One patient was converted to general anesthesia due uncontrolled seizures. All the patients were shifted to the intensive care unit for further observation. The patients' haemodynamic parameters were stable throughout the procedure. The post-operative course was uneventful and discharged after 5 days.

Case No. 1: BIS Monitoring (Spacelab work station with inbuilt BIS module)
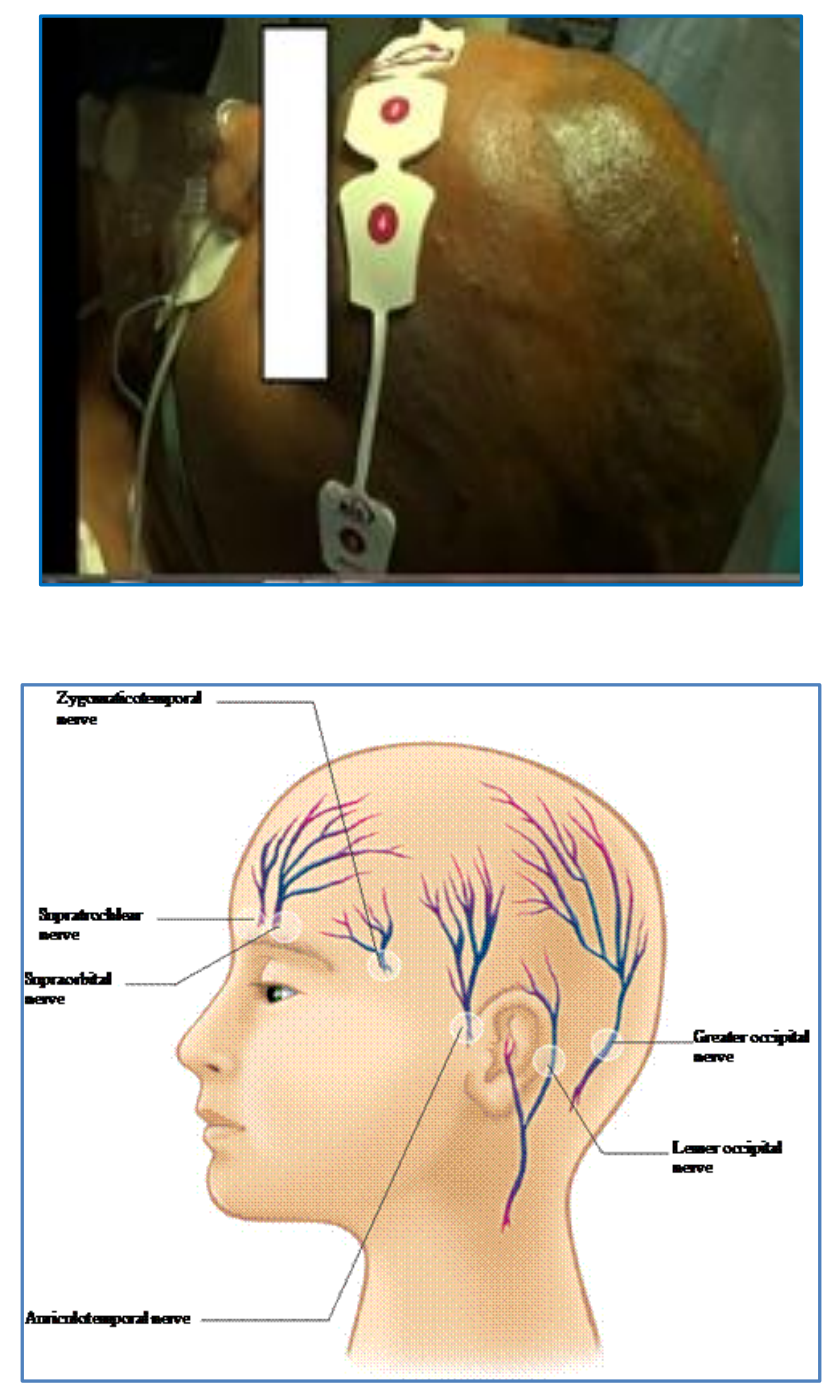

Fig: Innervation of the scalp for scalp block 
Case No. 2: Positioning for awake craniotomy.

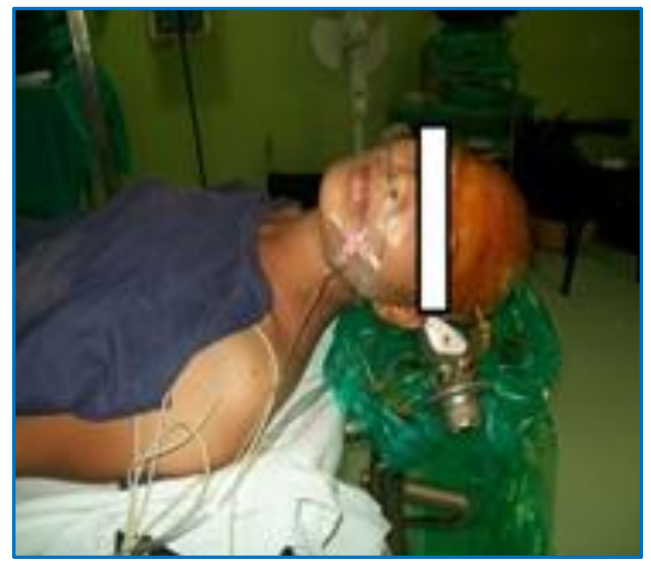

Case No. 2

DISCUSSION: Although awake craniotomy is well established for epilepsy surgery, only recently it has become more popular for resection of brain tumors involving eloquent areas and removal of supratentorial tumors. ${ }^{5}$ The benefits include an increased lesion removal, improved survival benefit ${ }^{1}$, shorter hospitalization time, reduced cost and a decreased incidence of postoperative complications. ${ }^{6}$ One of the most important considerations for awake craniotomy is careful patient selection. The patient should cooperate in an unfamiliar and stressful environment for an extended period of time. Infact, the only absolute contraindication for awake technique is an uncooperative patient. ${ }^{7}$ A Our anesthesia team in preoperative visit detailed about expected discomforts and level of co-operation expected, potential and tasks that will be performed for motor testing.

Several studies have endorsed the use of propofol for awake craniotomy. ${ }^{8}$ The use of propofol reduced the incidence of perioperative seizures and agitation, but led to a frequent incidence of respiratory depression. More recently, the combination of propofol and remifentanil has been successfully used for brain tumor mapping. Remifentanil's context-sensitive half-life is short ( $<5$ minutes) allows a rapid modulation of analgesia and sedation. The side effects of remifentanil, however, are similar to those of all fentanyl congeners. The patients in both studies had episodes of respiratory depression, airway obstruction, and desaturation. ${ }^{9}$

Dexmedetomidine is a highly specific $\alpha_{2}$-adrenoreceptor agonist with sedative, analgesic, and anesthetic-sparing effects. ${ }^{10}$ It does not suppress ventilation. The primary action is excitation inhibition in the central nervous system. It is a cerebral vasoconstrictor by stimulating $\alpha 2 \mathrm{~b}$ receptors in the cerebral blood vessels with no effect on CMRO2. Dexmedetomidine inhibits the cerebral vasodilatation induced by hypercapnia, thus avoiding increased intracranial pressure and brain bulging. Small-dose infusion of this drug in healthy volunteers provided sedation that could be easily reversed with verbal stimuli. ${ }^{11}$

We anticipated that the patient treated with dexmedetomidine would be sedated and comfortable but easily arousable to tolerate a prolonged awake craniotomy. In our case series the level of sedation during Dexmedetomidine infusion was monitored by BIS index, maintained BIS score between 70-90 by increasing level of sedating during positioning and head pin fixation and reducing it during testing for functional area intraoperatively. ${ }^{12}$ 
Patient tolerance of an awake craniotomy relies on effective analgesia of the surgical field, and cannot rely on sedation or anaesthesia alone. ${ }^{5}$ In our case scalp block combined with local infiltration provided adequate analgesia, haemodynamic stability and decreased the stress response to painful stimuli.

Complications of awake craniotomy include seizures, cerebral edema, nausea and vomiting, decreased level of consciousness, neurological deficit, pain, and loss of patient cooperation.1,13 Airway management is uneventful during awake craniotomy under sedation in our reported cases. However, over sedation inevitably runs the risk of apnoea and airway obstruction. Airway obstruction (Incidence $0 \%$ to $20 \%$ ) with oxygen desaturation (0-28\%) may result in brain swelling because of elevated levels of PaCO2.14 Equipment for emergency airway control should be available throughout awake craniotomy.

Seizures may occur unexpectedly ( $0 \%$ to $24 \%$ ) due to decreased levels of anticonvulsants or local anesthetic toxicity. Most of the seizures can be resolved by irrigation of the surgical field with cold saline or administration of propofol. ${ }^{14}$ An antiepileptic prophylaxis may be helpful to prevent intraoperative seizures. However, one of reported cases developed uncontrolled seizures in spite of prophylactic measures. Local anesthetic toxicity is ruled out because dose administered was not exceeded maximum limit and adrenaline ( $5 \mu \mathrm{g} / \mathrm{ml}, 1: 200,000$ dilutions) was added to local anesthetic solution both to minimizes acute rises in plasma concentration and maximizes the duration of block.

During the procedure precautions were taken to prevent shivering by using warm infusions and blanket ${ }^{1}$. Dexmedetomidine can cause hypotension and bradycardia. ${ }^{15}$ However the patients in our case series were hemodynamically stable.

CONCLUSIONS: Dexmedetomidine provides adequate sedation without airway compromise during awake craniotomy for tumour resection. An effective scalp block provides additional analgesia that enhances patient comfort. Titrating depth of sedation using BIS is useful even if clinical observation of vital signs and specific sedation scores are adequate. In this case series no untoward incidents were noticed and patient cooperation and satisfaction was excellent.

\section{REFERENCES:}

1. Piccioni F, Fanzio M. Management of anaesthesia in awakecraniotomy. Minerva Anestesiol. 2008; 74: 393-408.

2. Frost EAM, Booij LHDJ. Anesthesia in the patient for awake craniotomy. Curr Opin Anaesthesiol. 2007; 20: 331-5.

3. Conte V, Baratta P, Tomaselli P, et al. Awake neurosurgery: an update. Minerva Anestesiol. 2008; 74: 289-92.

4. Sebbel PSL and E Ramphil IJ et al. A multicenter study of bispectral electroencephalogram analysis for monitoring anesthesia effect. Anesthesia and Analgesia 1997; 84: 891-9.

5. Costello TG, Cormack JR. Anaesthesia for awake craniotomy: a modern approach. J Clin Neurosci 2004; 11: 16-9.

6. Blanshard HJ, Chung F, Manninen PH, Taylor MD, Bernstein M. Awake craniotomy for removal of intracranial tumor: Considerations for early discharge. Anesth Analg. 2001; 92: 89-94.

7. Sarang A, Dimsmore A-Anesthesia for awake craniotomy-evolution of a technique that facilitates awake neurological testin. British J Anaesth 2003; 90 (2): 161-5. 
8. Silbergeld DL, Mueller WM, Colley PS, et al. Use of propofol (Diprivan) for awake craniotomies: technical note. Surg Neurol 1992; 38: 271-2.13.

9. Manninen PH, Balki M, Lukitto K, Bernstein M. Patient satisfaction with awake craniotomy for tumor surgery: A comparison of remifentanil and fentanyl in conjunction with propofol. Anesth Analg. 2006; 102: 237-42.

10. Belleville JP, Ward DS, Bloor BC, Maze M. Effects of intravenous dexmedetomidine in humans. Sedation, ventilation, and metabolic rate. Anesthesiology 1992; 77: 1125-33.

11. Hall EJ, Uhrich TD, Barney JA, et al. Sedative, amnestic, and analgesic properties of small-dose dexmedetomidine infusions. Anesth Analg 2000; 90: 699-705.

12. Hans P, Bonhomme V, Born JD, et al. Target-controlled infusion of propofol and remifentanil combined with bispectral index monitoring for awake craniotomy. Anaesthesia 2000; 55: 25.

13. Bekker A, Sturaitis MK. Dexmedetomidine for neurological surgery. Neurosurgery 2005; 5.

14. Sartorius CJ, Berger MS. Rapid termination of intraoperative stimulation - Evoked seizures with application of cold Ringer's lactate to the cortex. J Neurosurg. 1998; 88: 349-51.

15. Talke $\mathrm{P}$, Chen $\mathrm{R}$, Thomas $\mathrm{B}$, et al. The hemodynamic and adrenergic effects of perioperative dexmedetomidine infusion after vascular surgery. Anesth Analg 2000; 90: 834-9.

\section{AUTHORS: \\ 1. B. Annapurna Sarma \\ 2. P. Sateesh Kumar \\ 3. B. Muralikrishna}

\section{PARTICULARS OF CONTRIBUTORS:}

1. Associate Professor, Department of Anaesthesiology, Andhra Medical College, Visakhapatnam, Andhra Pradesh, India.

2. Assistant Professor, Department of Anaesthesiology, Andhra Medical College, Visakhapatnam, Andhra Pradesh, India.
3. Professor, Department of Anaesthesiology, Andhra Medical College, Visakhapatnam, Andhra Pradesh, India.

\section{NAME ADDRESS EMAIL ID OF THE CORRESPONDING AUTHOR:}

Dr. B. Annapurna Sarma, Flat No. 203, 15-7-3/5, Jayanti Exclave, Krishna Nagar, Maharanipet, Visakapatnam-530002.

E-mail: drbasarma@yahoo.com

Date of Submission: 02/06/2015. Date of Peer Review: 03/06/2015. Date of Acceptance: 17/06/2015. Date of Publishing: 24/06/2015. 